> Continuar con la labor de integración de la información patrimonial, para ello el SIPHA deberá integrarse con otros sistemas de información de la Consejería de Cultura (información de la gestión, de las colecciones de las instituciones patrimoniales, etc.)

> Realizar una evaluación periódica del Sistema para detectar fallos, errores, vacios, etc. y poder asi adaptarlo a las necesidades que sus usuarios vayan planteando.
> Articular estrategias para lograr una actualización de la información de forma descentralizada a través de proyectos propios y de colaboración con otros organismos y administraciones.

$>$ Y, por último, potenciar la línea de análisis de la información con objeto de promover la elaboración de directrices y orientaciones para la tutela del Patrimonio Histórico.

\title{
La Base de Datos del Patrimonio Inmueble de Andalucía estará disponible en Internet
}

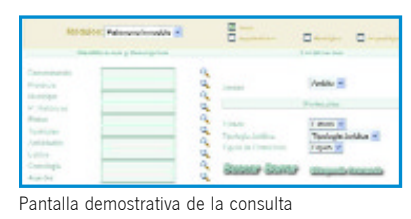

Pantalla demostrativa de la consulta
Durante el primer trimestre del 2004 estará disponible en la página Web del Instituto Andaluz del Patrimonio Histórico (http://www. juntadeandalucia.es/cultura/iaph) una nueva aplicación de acceso en línea a las bases de datos del Sistema de Información del Patrimonio Histórico de Andalucia (SIPHA). La información que se podrá consultar será la correspondiente al Patrimonio Inmueble en su modalidad de Arquitectónico, Arqueológico y Etnológico. En fases posteriores se completará con el acceso a la información del Patrimonio Mueble y de las Ciudades Históricas, dentro de un proyecto global que consiste en presentar la información del Patrimonio Histórico Andaluz de una forma integrada. Además de la información relativa a los bienes culturales, se encuentra disponible desde diciembre de 2003 una aplicación de consulta a la base de datos del Tesauro del Patrimonio Histórico Andaluz.

Para conocer los requerimientos para el manejo de la aplicación relativa al Patrimonio Inmueble, inicialmente se accederá a una primera pantalla de presentación, en la que se explicará al usuario los contenidos que puede encontrar, además de ofrecerle unas instrucciones para el correcto desarrollo de la consulta.

El usuario tendrá la posibilidad de determinar la búsqueda eligiendo una de las tres opciones 0 modalidades (Patrimonio Arquitectónico, Patrimonio Arqueológico, y Patrimonio Etnológico) por separado, o bien realizando combinaciones por pares, o por todas conjuntamente.

Según la opción seleccionada, encontraremos una ecuación de búsqueda con los campos concretos de dicha modalidad.
En una primera fase, se realizarán búsquedas libres o "a la carta", en modo simple o avanzado, teniendo en este caso la posibilidad de utilizar operadores booleanos entre los campos.

En cuanto a la recuperación de la información, una vez efectuada la búsqueda se presentará una lista de resultados con un número total de registros y los campos básicos de identificación de los mismos.

Presentada esta Lista de Resultados, podremos Marcar y seleccionar uno o varios registros para su visualización. Por defecto, en esta primera fase, se visualizará una información básica de los bienes.

Se podrán ver todos los registros de un modo secuencial (de uno en uno), o ver únicamente aquellos registros seleccionados o marcados. Además, está prevista la incorporación de imágenes asociadas a los bienes.

Un nuevo avance en la aplicación supondrá la realización de búsquedas predeterminadas con varias posibilidades de elección, atendiendo a los aspectos más requeridos por los usuarios. Del mismo modo, en una segunda fase, se ampliará la información de los informes de los bienes resultantes.

Finalmente, cabe destacar las posibilidades de imprimir o de guardar la información seleccionada, así como de volver al punto de partida o a la Página Principal del IAPH para consultar otras de las informaciones y contenidos disponibles

Isabel Ortega y Susana Limón Centro de Documentación del IAPH

\footnotetext{
Cuadernos del IAPH

Puede encontrar más información sobre estas colecciones de monografías especializadas en: www.iaph.junta-andalucia.es/publicaciones/form_ibol.html

Si desea adquirir alguno de los números puede contactar con:

Editorial Comares

Tel.: 958465382 Correo-e: pedidos@comares.com Web: www.comares.com
} 